\title{
ノート
}

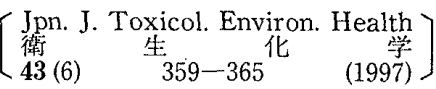

- Notes-

\section{Mutagenicity of an Ozonized Solution of Phenylenediamine Derivatives in the Salmonella Test}

\author{
Hiroshi Kami, ${ }^{*} a$ Tetsushi Watanabe ${ }^{b}$ and Teruhisa Hirayama ${ }^{b}$ \\ Shiga Research Laboratories, Schering-Plough Kabusiki Kaisha, ${ }^{a}$ 1-4 \\ Sasagaoka, Minakuchi-cho, Koga-gun, Shiga 528, Japan \\ Kyoto Pharmaceutical University," 5 Nakauchi-cho, \\ Misasagi, Yamashina-ku, Kyoto 607, Japan
}

(Received June 30, 1997)

\begin{abstract}
$o$-Phenylenediamine (o-PD), $m$-phenylenediamine $(m$-PD), 2,4-diaminotoluene (DAT) or

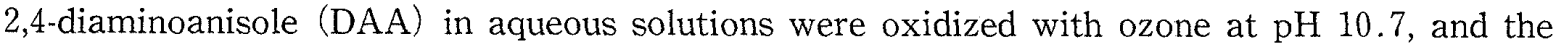
ozonized solutions were tested for their mutagenicity in Salmonella typhimurium TA 98 in the presence or absence of a mammalian metabolic activation system ( $\mathrm{S} 9 \mathrm{mix}$ ). The mutagenicity of $m$-PD and DAA aqueous solutions with S 9 mix was markedly enhanced by oxidation with 1 - to 4 -fold mol of ozone, but vanished with sufficient ozonation. An aqueous solution of $m$-PD and DAA was ozonized at $\mathrm{pH} 4.0,7.0$ and 10.7 , and the mutagenicity of the ozonized solution and extract with ethyl acetate (AcOEt) was tested in S. typhimurium TA 98 with S 9 mix. At all pH values of the solution, mutagenicity was markedly enhanced by ozonation, and that of the AcOEt extract was equal to or greater than that of the aqueous solution. Aminophenazines were observed in the AcOEt extract from the ozonized solution of $m$-PD and DAA. The contribution of the aminophenazines to mutagenicity, however, was low, and it is suggested that other major mutagenic compounds were formed.
\end{abstract}

Key words — phenylenediamine derivative; ozonation; mutagenicity; Salmonella/microsome test

\section{Introduction}

Phenylenediamine (PD) derivatives are used widely as ingredients in dyes, paints and resins in industrial organic synthesis. Ames et al. ${ }^{1)}$ reported that 9 kinds of PD derivatives, such as $0-\mathrm{PD}$, $m$-PD, 2,4-diaminotoluene (DAT) and 2,4-diaminoanisole (DAA), showed various degrees of mutagenicity, and that industrial waste water containing these chemicals should therefore be properly treated to degrade them. Pitter and Radkova $^{2)}$ reported that PD derivatives were not degradable by biological purification and that chemical methods were required for waste water treatment. Chlorination has been the most com- monly performed chemical treatment process for waste water. It was pointed out, however, that the chlorination of waste water produces several mutagenic and/or carcinogenic compounds as by-products., ${ }^{3,4}$ Ozonation has recently been utilized as a replacement for chlorination. Burleson and Chambers ${ }^{5)}$ reported that ozonation inactivated or reduced the mutagenicity of several polyaromatic amines at an ozone dose of $45 \mathrm{mg} \mathrm{O} \mathrm{O}_{3}$ per mg compound or higher. However, the ozone dose is often less than $1 \mathrm{mg} \mathrm{O}$ per $\mathrm{mg}$ of total organic carbon in water treatment, and ozonation byproducts will be formed. Azobenzenes, azoxybenzenes, benzidines and phenazines were determined to be reaction products from an aqueous solution 
of anilines treated with ozone. ${ }^{6)}$ Highly genotoxic products such as formaldehyde, acetaldehyde, glyoxal and methylglyoxal were also isolated from the ozonation of sewage or humic solution. ${ }^{\text {?) }}$ In our previous paper, ${ }^{8-10)}$ we reported that the mutagenicity of $m$-PD, $o$-PD, DAT and DAA was markedly enhanced by gentle oxidation using diluted hydrogen peroxide $\left(\mathrm{H}_{2} \mathrm{O}_{2}\right)$, and the major mutagenic compounds in oxidized PD derivatives were confirmed to be aminophenazines.

The purpose of this study was to investigate the mutagenicity of $m-\mathrm{PD}, o-\mathrm{PD}, \mathrm{DAT}$ and DAA treated with ozone oxidation. The ozonation of PD derivatives was conducted in a heterogeneous system. In the case of the ozonation of anilines, the yields of azobenzenes and azoxybenzenes produced were highest at a high $\mathrm{pH}$ by shifting the oxidation mechanism toward the $\mathrm{OH}$ radicals. ${ }^{6)}$ The aqueous solutions of $\mathrm{PD}$ derivatives were therefore ozonized at $\mathrm{pH}$ 10.7. The effect of the $\mathrm{pH}$ of aqueous solutions on the mutagenicity of $\mathrm{PD}$ derivatives was tested in the case of $m$-PD and DAA. Mutagenicity and the amount of aminophenazines in AcOEt extracts from ozonized $m$-PD and DAA solutions were also determined, and the contributions of aminophenazines to mutagenicity were estimated.

\section{Materials and Methods}

Chemicals $o$-Phenylenediamine dihydro- chloride $(o$-PD $), m$-phenylenediamine dihydrochloride $(m-\mathrm{PD})$ and $\beta$-naphthoflavone $(\beta$-NF) were purchased from Nacalai Tesque (Kyoto, Japan). 2,4-Diaminotoluene (DAT), 2,4diaminoanisole dihydrochloride (DAA), 4-nitroquinoline $N$-oxide $(4 \mathrm{NQO})$, and 2 -acetylaminofluorene (AAF) were purchased from Tokyo Kasei (Tokyo, Japan). Spectrophotometric-grade dimethyl sulfoxide (DMSO), polychlorobiphenyl, penta (PCB) and phenobarbital (PB) were purchased from Wako Pure Chemicals (Osaka, Japan). 2,7-Diaminophenazine, 2,7diamino-3-methoxyphenazine and 2,7-diamino3,8-dimethoxyphenazine were prepared according to the method described in our previous papers. ${ }^{11}$

Ozonation of Phenylenediamine Derivatives

Figure 1 shows the structure, abbreviations and CAS registry numbers of the PD derivatives tested. Each $0.1 \mathrm{mmol}$ of $\mathrm{PD}$ derivative was dissolved in $40 \mathrm{ml}$ of $0.01 \mathrm{~m}$ phosphate buffer $(\mathrm{pH}$ 4.0, 7.0 and 10.7), and ozone was applied directly to the solution for zero to $8 \mathrm{~min}$. Ozone was generated by an ozone generator (Type O-3-2, Nihon Ozone K. K., Japan) at an air flow rate of $1 \mathrm{l} / \mathrm{min}$. The molar ratio of the applied ozone relative to PD derivatives was calculated as follows: ozone was applied to an ozone absorbing solution, and the amount of absorbed ozone was determined by the KI method as described in<smiles>[R]c1ccc(N)c([R2])c1[R]</smiles>

\begin{tabular}{llllll}
\hline Sample & $\mathrm{R}_{1}$ & $\mathrm{R}_{2}$ & $\mathrm{R}_{3}$ & Abbreviation & CAS No. \\
\hline o-Phenylenediamine & $\mathrm{NH}_{2}$ & $\mathrm{H}$ & $\mathrm{H}$ & o-PD & $95-54-5$ \\
m-Phenylenediamine & $\mathrm{H}$ & $\mathrm{NH}_{2}$ & $\mathrm{H}$ & $m$-PD & $108-45-2$ \\
2,4-Diaminotoluene & $\mathrm{H}$ & $\mathrm{NH}_{2}$ & $\mathrm{CH}_{3}$ & 2,4-DAT & $95-80-7$ \\
2,4-Diaminoanisole & $\mathrm{H}$ & $\mathrm{NH}_{2}$ & $\mathrm{OCH}_{3}$ & 2,4-DAA & $615-05-4$ \\
\hline
\end{tabular}

Fig. 1 The Structure of Phenylenediamine Derivatives 
Standard Methods of Analysis for Hygienic Chemists ${ }^{12)}$. After ozonation, the remaining ozone was removed from the PD derivative solutions by $\mathrm{N}_{2}$ gas induction. The reaction mixture was made up to $50 \mathrm{ml}$ with buffer before the mutagenicity test and ethyl acetate (AcOEt) extraction.

Determination of Aminophenazines and Phenylenediamine Derivatives Ozonized solutions of $\mathrm{PD}$ derivatives at $\mathrm{pH} 7.0$ or 10.7 were extracted directly with $40 \mathrm{ml}$ of AcOEt twice, and the ozonized solution at $\mathrm{pH} 4.0$ was neutralized with sodium hydroxide before AcOEt extraction. The AcOEt layers were evaporated to dryness and the extract was re-dissolved in methanol for HPLC analysis. The determination of aminophenazines and PD derivatives was performed on an STR ODS-H column ( $5 \mu \mathrm{m}$ particle size, $150 \times 4.0$ mm i.d., Shimadzu Techno Research, Inc., Japan) by an LC-10 HPLC System (Shimadzu, Japan). The elution was performed at ambient temperature with $20 \%$ acetonitrile solution as the mobile phase at a flow rate of $0.7 \mathrm{ml} / \mathrm{min}$. Aminophenazines were monitored with a fluorescence detector (F 1000, Hitachi, Japan, excitation $490 \mathrm{~nm}$, emission $580 \mathrm{~nm}$ ) and $\mathrm{PD}$ derivatives were monitored with a UV detector (SPD-10 AV, Shimadzu) at $254 \mathrm{~nm}$.

Mutagenicity Test — For the mutagenicity test, a portion of freshly ozonized aqueous solution of PD derivatives was sterilized with a membrane filter (pore size : $0.45 \mu \mathrm{m}$ ) and diluted with $0.1 \mathrm{~m}$ phosphate buffer. Forty $\mathrm{ml}$ of ozonized aqueous solution was extracted with AcOEt in the same way as described above. After the evaporation of AcOEt layers, the residues were dissolved in sterile DMSO. Each $0.1 \mathrm{ml}$ of aqueous or DMSO solution was subjected to the mutagenicity test. The mutagenicity test was performed essentially by the Ames method ${ }^{13)}$ using the suspension assay as modified by Yahagi. ${ }^{14)}$ The tester strain, Salmonella typhimurium TA 98, was checked routinely to confirm its genetic features for optimal response with positive controls, 4 NQO $(0.5$ $\mu \mathrm{g} / \mathrm{plate})$ and $\mathrm{AAF}(5 \mu \mathrm{g} / \mathrm{plate})$. The assay was performed in the absence or presence of S 9 mix to simulate mammalian metabolism. Each dose level of the sample solutions was assayed in duplicate with at least three doses. The mutagenicity was demonstrated as numbers of revertant colonies per $0.1 \mathrm{ml}$ of undiluted solution, as calculated from those in each dilution showing a linear dose response curve.

Metabolic Activation System — The postmitochondrial fraction (S 9) was prepared from the liver of male Sprague-Dawley rats induced with $\mathrm{PCB}$ alone or $\mathrm{PB}$ and $\beta-\mathrm{NF}$ in combination. ${ }^{15)}$ The homogenate was centrifuged as described by Ames et al. ${ }^{13)}$ Preparation of the S 9 mix was performed according to Yahagi ${ }^{14)}$. One $\mathrm{ml}$ of $\mathrm{S} 9$ mix contained $8 \mu \mathrm{mol} \mathrm{MgCl}_{2}, 33 \mu \mathrm{mol}$ $\mathrm{KCl}, 5 \mu \mathrm{mol}$ glucose-6-phosphate, $4 \mu \mathrm{mol}$ NADPH, 0.5 unit glucose-6-phosphate dehydrogenase, $150 \mu \mathrm{mol}$ sodium phosphate buffer (pH 7.4), water and $50 \mu 1$ of S 9 .

\section{Results and Discussion}

Mutagenicity and Residual PD Derivatives in an Ozonized Aqueous Solution of $m$-PD, o-PD, DAT and DAA

Table 1 shows the mutagenicity per $0.1 \mathrm{ml}$ of aqueous solutions of $\mathrm{PD}$ derivatives which were treated with zero to 32 -fold mol of ozone at $\mathrm{pH}$ 10.7 in S. typhimurium TA 98 with or without S 9 mix. The mutagenicity of PD solutions was calculated from the linear portion of the dose-response curve.

The mutagenicity of an aqueous solution of $m$-PD with S 9 mix was markedly enhanced by ozonation with 1 - to 2 -fold mol of ozone. The mutagenicity then decreased with further ozonation and vanished with 8 -fold mol of ozone. A similar phenomenon was observed with DAAozonation; the mutagenic potency of DAA aqueous solution with S 9 mix was increased 117 -fold or 152 -fold after ozonation at 1 - to 2 -fold mol of ozone, respectively. Aqueous solutions of both $o$-PD and DAT were mutagenic in strain TA 98 with $\mathrm{S} 9$ mix before ozonation (Sample/ $\mathrm{O}_{3}$ molar ratio $=1: 0$ ), and it was considered that either $o \cdot \mathrm{PD}$ and DAT alone were mutagenic by the metabolic activation of S 9 and/or were oxidized by air in solution. However, this mutagenicity 
Table 1. Mutagenicity and Residual Phenylenediamine (PD) Derivatives in Ozonized PD Aqueous Solutions in S. typhimurium TA98 with/without S9 Mix

\begin{tabular}{|c|c|c|c|c|}
\hline \multirow{2}{*}{ Sample ${ }^{a)}$} & \multirow{2}{*}{$\begin{array}{c}\text { Sample/O } \\
\text { (molar ratio) }\end{array}$} & \multicolumn{2}{|c|}{ net $\mathrm{His}^{+}$rev. $/ 0.1 \mathrm{ml}^{\circ)}$} & \multirow{2}{*}{$\begin{array}{c}\text { Residual PDs } \\
(\%)\end{array}$} \\
\hline & & $+\mathrm{S} 9 \mathrm{mix}^{c)}$ & $-\mathrm{S} 9 \mathrm{mix}$ & \\
\hline \multirow[t]{6}{*}{$o$-PD } & $1: 0$ & 268 & 0 & 100 \\
\hline & $1: 2$ & 311 & 0 & 19.6 \\
\hline & $1: 4$ & 201 & 0 & 0.6 \\
\hline & $1: 8$ & 4 & 0 & 0 \\
\hline & $1: 16$ & 0 & 0 & 0 \\
\hline & $1: 32$ & 0 & 0 & 0 \\
\hline \multirow[t]{7}{*}{$m-\mathrm{PD}$} & $1: 0$ & 62 & 8 & 100 \\
\hline & $1: 1$ & 1467 & 10 & 26.0 \\
\hline & $1: 2$ & 3114 & 13 & 6.5 \\
\hline & $1: 4$ & 1521 & 10 & 0.5 \\
\hline & $1: 8$ & 7 & 15 & 0 \\
\hline & $1: 16$ & 8 & 6 & 0 \\
\hline & $1: 32$ & 3 & 14 & 0 \\
\hline \multirow[t]{6}{*}{ DAT } & $1: 0$ & 125 & 0 & 100 \\
\hline & $1: 2$ & 143 & 16 & 27.0 \\
\hline & $1: 4$ & 126 & 0 & 7.8 \\
\hline & $1: 8$ & 27 & 0 & 0.2 \\
\hline & $1: 16$ & 27 & 0 & 0 \\
\hline & $1: 32$ & 0 & 0 & 0 \\
\hline \multirow[t]{7}{*}{ DAA } & $1: 0$ & 44 & 0 & 100 \\
\hline & $1: 1$ & 5184 & 5 & 27.3 \\
\hline & $1: 2$ & 6723 & 7 & 8.1 \\
\hline & $1: 4$ & 3024 & 11 & 0.4 \\
\hline & $1: 8$ & 756 & 11 & 0 \\
\hline & $1: 16$ & 18 & 0 & 0 \\
\hline & $1: 32$ & 5 & 12 & 0 \\
\hline
\end{tabular}

a) PD aqueous solutions: $0.1 \mathrm{mmol}$ of PD derivatives in $50 \mathrm{ml}$ of $0.1 \mathrm{~m}$ phosphate buffer (pH 10.7). $b$ ) spontaneous revertants: + S9 mix, 23 to $44 \mathrm{rev} / \mathrm{plate}$; $-\mathrm{S} 9 \mathrm{mix}, 24$ to $43 \mathrm{rev} . / \mathrm{plate}$. c) $\mathrm{PCB}$ was used for S9 induction.

almost vanished by treatment with 8 -fold mol of ozone. On the other hand, very little mutagenicity was observed without $\mathrm{S} 9 \mathrm{mix}$ before or after the ozonation of all $\mathrm{PD}$ derivatives. $o$-PD, $m$-PD and DAA in solution vanished by treatment with 8 -fold mol of ozone, and DAT vanished by treatment with 16 -fold mol of ozone. In all the plates tested for the mutagenicity test, no bacterial toxicity was observed.

These results indicated that mutagenic compounds were formed by ozonation, especially in the case of $m$-PD and DAA. They were, however, degraded by sufficient ozonation.

Effect of the pH of an Aqueous Solution on Mutagenicity in the Ozonation of $m$-PD and DAA

Figures 2 and 3 show the mutagenicity of $m-\mathrm{PD}$ and DAA aqueous solutions treated with ozone at various $\mathrm{pH}$ values in the strain TA 98 with $\mathrm{S} 9$ mix. For $m$-PD, at both $\mathrm{pH} 7.0$ and 10.7 , mutagenicity was markedly enhanced by ozonation with 1- to 2-fold mol of ozone, but almost vanished by ozonation with 8 -fold mol of ozone. At pH 4.0, mutagenicity was also markedly enhanced by ozonation and was four or more times as strong as that at $\mathrm{pH} 7.0$ and 10.7. Moreover, 16 -fold mol of ozone was required for the mutagenicity to vanish. These results suggest that a similar reaction by ozone occurred at both $\mathrm{pH} 7.0$ and 10.7 , while a different reaction occurred at $\mathrm{pH} 4.0$. This difference at $\mathrm{pH} 4.0$ might be explained by the decomposition of ozone. Ozone was decomposed to form $\mathrm{OH}$ radical increases at a high $\mathrm{pH}$, while ozone was stable and direct oxida- 


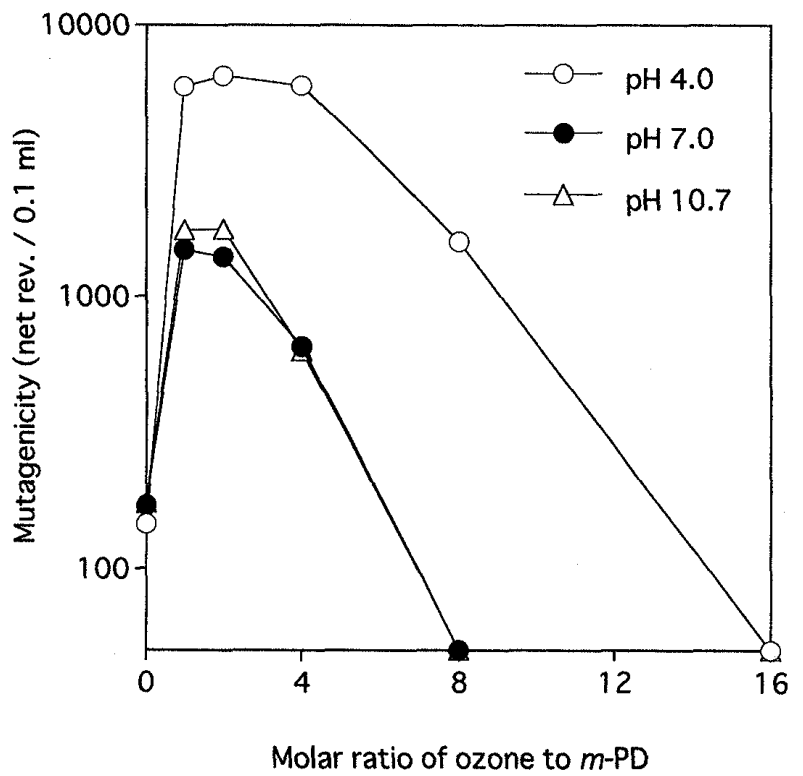

Fig. 2 Mutagenicity of Ozonized $m$-PD Aqueous Solutions ( $\mathrm{pH} 4.0,7.0,10.7$ ) in S. Typhimurium $\mathrm{TA} 98$ with $\mathrm{S} 9 \mathrm{Mix}$

$m$-PD aqueous solutions: $0.1 \mathrm{mmol}$ of $m$-PD in $50 \mathrm{ml}$ of $0.1 \mathrm{~m}$ phosphate buffer. $\mathrm{PB}$ and $\beta$-NF were used for $\mathrm{S} 9$ induction.

tion by ozone increased at a low $\mathrm{pH}$.

For DAA, mutagenicity was markedly enhanced by ozonation (1- and 2-fold mol of DAA) in all ranges of $\mathrm{pH}$, then vanished by ozonation with 8 -fold mol of ozone. The effect of the $\mathrm{pH}$ of an aqueous solution on the mutagenicity of ozonized DAA was not observed. It was suggested that similar mutagenic compounds were formed, in spite of different reaction pathways at each $\mathrm{pH}$ and/or that different compounds formed in all ranges of $\mathrm{pH}$ had similar mutagenicity.

Regardless of $\mathrm{pH}$ conditions, the mutagenicity of an aqueous solution of $m-\mathrm{PD}$ and DAA was markedly enhanced by ozonation, but then vanished by treatment with sufficient amounts of ozone.

Mutagenicity and Aminophenazines in AcOEt Extracts from Ozonized Aqueous Solutions of $m$-PD and DAA

Table 2 shows the mutagenicity of AcOEt extracts from ozonized aqueous solutions of $m$-PD and DAA which were treated with one or 2 -fold mol of ozone. The mutagenicity of the AcOEt extracts was converted to that equivalent to $0.1 \mathrm{ml}$ of ozonized aqueous solution. Table 2

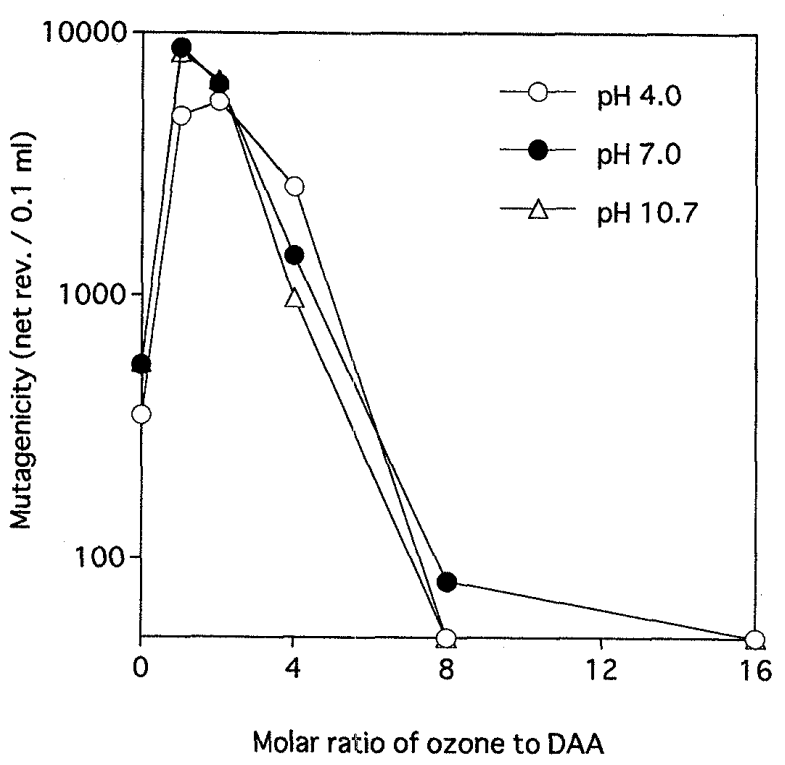

Fig. 3 Mutagenicity of Ozonized DAA Aqueous Solutions ( $\mathrm{pH} 4.0,7.0,10.7$ ) in S. Typhimurium $\mathrm{TA} 98$ with $\mathrm{S} 9 \mathrm{Mix}$

DAA aqueous solutions : $0.1 \mathrm{mmol}$ of DAA in $50 \mathrm{ml}$ of $0.1 \mathrm{~m}$ phosphate buffer. $\mathrm{PB}$ and $\beta$-NF were used for S9 induction.

also shows the amount of aminophenazines, which are the major mutagenic products in the treatment of PD derivatives with $\mathrm{H}_{2} \mathrm{O}_{2}{ }^{9}{ }^{9}$ The ratios of the contribution of aminophenazines to the mutagenicity of the aqueous solutions with S9 mix were estimated from the mutagenicity of the aminophenazines tested at the same time.

For $m-\mathrm{PD}$, the mutagenicity of AcOEt extracts was similar to that of the aqueous solution ozonized at $\mathrm{pH} 4.0$, and was 1.5- to 2-fold as high as that of the solution ozonized at $\mathrm{pH} 7.0$ and 10.7. 2,7-Diaminophenazine ( $135000 \mathrm{rev} / \mu \mathrm{g})$ was formed by ozonation, but the ratio of contribution to mutagenicity was low, at 4.7 to $9.7 \%$ at all $\mathrm{pH}$ values. For DAA, the mutagenicity of AcOEt extracts was 2- to 3-fold as high as that of the aqueous solution at all $\mathrm{pH}$ values. 2,7-Diamino3-methoxyphenazine (1674 rev. / $/ \mathrm{g})$ and 2,7diamino-3, 8-dimethoxyphenazine (70 rev. $/ \mu \mathrm{g})$ were also formed, but the ratio of contribution to mutagenicity after ozonation was low, at 10.1 to $21.3 \%$ at all $\mathrm{pH}$ values.

These results suggest that mutagenic and antimutagenic compounds might have been formed simultaneously by the ozonation of $m$-PD and 
Table 2. Mutagenicity and Aminophenazines in AcOEt Extracts from Ozonized Aqueous Solutions of $m$-PD and DAA in S. typhimurium TA98 with S9 Mix

\begin{tabular}{|c|c|c|c|c|c|c|c|c|}
\hline \multirow[b]{3}{*}{ Sample ${ }^{a)}$} & \multirow[b]{3}{*}{$\mathrm{pH}$} & \multirow{3}{*}{$\begin{array}{c}\text { Sample } / \mathrm{O}_{3} \\
\text { (molar ratio) }\end{array}$} & \multirow{3}{*}{$\begin{array}{l}\text { Mutagenicity } \\
\text { of aqueous } \\
\text { solution } \\
\text { (net rev. } / 0.1 \mathrm{ml} \text { ) }\end{array}$} & \multicolumn{5}{|c|}{ AcOEt extract } \\
\hline & & & & \multicolumn{2}{|c|}{ Mutagenicity } & \multicolumn{3}{|c|}{ Aminophenazines ${ }^{c)}$} \\
\hline & & & & $\begin{array}{l}\text { Net rev./ } \\
0.1 \mathrm{ml}^{b)}\end{array}$ & $\begin{array}{l}\text { Ratio to } \\
\text { aqueous } \\
\text { solution }\end{array}$ & Content & $(\mu \mathrm{g} / \mathrm{ml})$ & $\begin{array}{c}\text { Ratio of } \\
\text { contribution to } \\
\text { mutagenicity }\end{array}$ \\
\hline \multirow[t]{6}{*}{$m-\mathrm{PD}$} & 4.0 & $1: 1$ & 2620 & 2457 & $93.8 \%$ & & 443 & $7.9 \%$ \\
\hline & & $1: 2$ & 3022 & 2889 & $95.6 \%$ & & 074 & $9.7 \%$ \\
\hline & 7.0 & $1: 1$ & 1002 & 2223 & $221.9 \%$ & & 098 & $6.7 \%$ \\
\hline & & $1: 2$ & 948 & 1741 & $183.6 \%$ & & 810 & $6.3 \%$ \\
\hline & 10.7 & $1: 1$ & 833 & 1367 & $164.1 \%$ & & 690 & $6.8 \%$ \\
\hline & & $1: 2$ & 949 & 1434 & $151.1 \%$ & & 501 & $4.7 \%$ \\
\hline \multirow[t]{6}{*}{ DAA } & 4.0 & $1: 1$ & 4118 & 11798 & $286.5 \%$ & $0.936^{d)}$ & $3.756^{e)}$ & $15.5 \%$ \\
\hline & & $1: 2$ & 6098 & 14332 & $235.0 \%$ & 1.605 & 5.150 & $21.3 \%$ \\
\hline & 7.0 & $1: 1$ & 3418 & 8258 & $241.6 \%$ & 0.815 & 4.205 & $20.1 \%$ \\
\hline & & $1: 2$ & 3471 & 6741 & $194.2 \%$ & 0.469 & 2.905 & $14.7 \%$ \\
\hline & 10.7 & $1: 1$ & 4319 & 9475 & $219.4 \%$ & 0.908 & 4.843 & $19.6 \%$ \\
\hline & & $1: 2$ & 4634 & 10196 & $220.0 \%$ & 0.510 & 2.558 & $10.1 \%$ \\
\hline
\end{tabular}

$\mathrm{PB}$ and $\beta$-NF were used for S9 induction. a) aqueous solutions: $0.1 \mathrm{mmol}$ of $m$-PD or DAA in $50 \mathrm{ml}$ of $0.1 \mathrm{~m}$ phosphate buffer ( $\mathrm{pH} 4.0,7.0,10.7)$. b) Mutagenicity of AcOEt extract was converted to that per volume equivalent to $0.1 \mathrm{ml}$ of aqueous solution. c) Mutagenicity of aminophenazines in S. typhymurium TA98 with $\mathrm{S9} \mathrm{mix}: 2,7-$ diaminophenazine for $m$-PD, $135000 \mathrm{rev} / \mu \mathrm{g} ; 2$,7-diamino-3-methoxyphenazine for DAA, $1674 \mathrm{rev} / \mu \mathrm{g}$; 2,7-diamino-3, 8-dimethoxyphenazine for DAA, $70 \mathrm{rev} / \mu \mathrm{g}$. d) 2,7-diamino-3-methoxyphenazine. e) 2,7-diamino-3,8dimethoxyphenazine.

DAA solutions, and that the anti-mutagenic compounds were not extracted with AcOEt from the aqueous solution because of their high polarity. Most mutagenic compounds which were formed by the ozonation of $m-\mathrm{PD}$ and DAA aqueous solution were considered to be extractable with AcOEt. In addition, aminophenazines were also formed by the ozonation of the aqueous solution of PD derivatives, as in the case of $\mathrm{H}_{2} \mathrm{O}_{2}$ oxidation, and other major mutagenic products were also formed. Ozone is a strong oxidizing agent, and the reaction of ozone with dissolved organics in aqueous solution is considered in terms of two reaction pathways : direct reactions of ozone, and free radical reactions involving a hydroxy free radical intermediate. ${ }^{16)}$ This is expected to be the reason for the difference between the mutagenic products formed by ozonation and those by $\mathrm{H}_{2} \mathrm{O}_{2}$ oxidation, which is gentle oxidation.

We are now investigating the mutagenic products obtained from AcOEt extracts of an ozonized aqueous solution of $m$-PD and DAA, since these mutagenicities were markedly enhanced by ozonation. Furthermore, PD derivatives are considered to be mixed with each other or other organic compounds in actual wastewater, so that further studies on the ozonation of the mixture are required.

Acknowledgments The authors are grateful to Prof. B.N. Ames, University of California, Berkeley, CA (U.S.A.), who kindly supplied Salmonella typhimurium TA 98.

\section{References}

1) Ames B.N., Kammen H.O., Yamasaki E., Proc. Nat. Acad. Sci. U.S.A., 72, 2423 (1975).

2) Pitter P., Radkova H., Sb. Vys. Sk. Chem. -Technol. Praze, Technol. Vody, F19, 99 (1974).

3) Rook J.J., Water Treat. Exam., 23, 234 (1974).

4) Suzuki S., Yousui To Haisui, 35, 575 (1993).

5) Burleson G.R., Chambers T.M., Envir. Mutagen, 4, 469 (1982). 
6) Chan W.F., Larson R.A., Water Res., 25, 1529 (1991).

7) Sayato Y., Jpn. J. Toxicol. Environ. Health, 39, 251 (1993).

8) Watanabe T., Ono T., Hirayama T., Fukui S., Mutat. Res., 190, 113 (1987).

9) Watanabe T., Hirayama T., Fukui S., Mutat. Res., 227, 135 (1989).

10) Watanabe T., Hirayama T., Fukui S., Mutat. Res., 245, 15 (1990).

11) Watanabe T., Hanasaki Y, Hirayama T., Fukui S., Mutat. Res., 225, 75 (1989).

12) The Pharmaceutical Society of Japan (ed.), "Standard Methods of Analysis for Hygienic Chemists", Kanehara Shuppan, Tokyo, 1990, p.1368.

13) Maron D.M., Ames B.N., Mutat. Res., 113, 173 (1983).

14) Yahagi T., Tanpakushitsu Kakusan Koso, 20, 1178 (1975).

15) Matsushima T., Sawamura M., Hara K., Sugimura T., "In Vitro Metabolic Activation in Mutagenesis Testing”, ed. by Serres F. J., Fouts J.R., Bend J.R., Philpot R.M., Elsevier/ North-Holland, Amsterdam, 1976, p.85.

16) Hoigné J., Badar H., Ozone: Sci. \& Eng., 1, 73 (1979). 